\section{INSTANT STRENGTH IONOMER}

Fuji Ortho LC is the first light-cured, resin reinforced glass ionomer for bracket bonding. Now you can work faster and easier while securing the full strength needed without decalcification (white spots) at debonding. Fuji Ortho LC delivers benefits that composites cannot claim.

Fuji Ortho LC is moisture friendly so it bonds perfectly in a wet field. It can be used with either a non-etch or etch technique and no separate bonding agent is needed. Because it is less technique sensitive you can dramatically reduce chairside time.

Fuji Ortho LC light cures in 20-40 seconds with instant strength and the material will even set chemically in the absence of light. You can insert levelling wire during the same visit.

Advanced glass ionomer technology bonds brackets with ample strength for even the most aggressive treatment, yet is easy to remove at case completion without damaging the enamel. Final clean up is fast and trouble-free.

After many years of clinical trials brackets were debonded without decalcification. Fuji Ortho LC releases significant levels of fluoride to help prevent decalcification and decay. Plus the fluoride toothpastes and mouthrinses actually recharge its fluoride release capacity.

Reader response number 53

\section{STRONG, RELIABLE RESTORATIONS}

ChemFil Rock from Dentsply is a glass ionomer restorative that offers clinicians a fast, economical alternative to composite restorations.

ChemFil Rock is an ideal choice for compromised situations. The unique zinc reinforced formula provides up to $25 \%$ higher strength than other conventional glass ionomer restoratives and demonstrates earlier build up to fracture toughness within the first crucial few hours, giving you the confidence in the longevity of the restoration and the patient superior wear resistance. ChemFil Rock achieves excellent clinical results without the need for cavity conditioning or final coating. ChemFil Rock has a non-sticky packable consistency and can be sculpted immediately.

Available in an easy to use capsule, ChemFil Rock is an adhesive glass ionomer restorative material that provides an efficient and reliable restoration.

Reader response number 54

\section{SINGLE USE BURS} AND FILLERS FOR ALL

The Dental Directory provides a range of UnoDent single use, sterile diamond, tungsten carbide and steel burs. These burs are available in packs of 25 and in various patterns. By supplying these instruments in bulk packs The Dental Directory is able to achieve the economy needed for a disposable bur without compromising on quality, at a reasonable price whatever your budget.

The Dental Directory also provides a variety of fillers to suit every patient. The UnoDent Nano Ceramic Restorative LC is a light-cured filling material based on Nano-Ceramic fillers. With 78\% inorganic filler material (ca. $0.7 \mu \mathrm{m}$ ), good biocompatibility and low shrinkage, the Nano-Ceramic LC is available in practical syringes and capsule format.

Also available is Nano Ceramic LC Flow, a flowable, light-curing filling material, suitable for anterior and posterior teeth. Again, based on Nano-Ceramic fillers, containing 64\% inorganic filler material (ca. $0.7 \mu \mathrm{m}$ ).

Like the Nano-Ceramic LC, the LC Flow combines superior quality ingredients with good biocompatibility and low shrinkage. It is also thixotropic, with fine-flow and excellent wetting capability.

Reader response number 55

\section{GAIN RESTORATIVE KUDOS}

Following significant success in previous years, Dentsply is once again running the popular Ceram.X Global Case Contest during 2011-2012 to provide current dental students with the opportunity to demonstrate their restorative skills, using the innovative nano-ceramic composites, Ceram.X Duo and Ceram.x Mono.

To compete to be the best Dentsply Ceram.X dental student in the world, entrants need to restore a tooth using Ceram.X Duo or Ceram.x Mono. The case must be presented using the poster template supplied by Dentsply with before and after photographs and a short description of each stage of the clinical procedure.

A maximum of three students can participate per school and each school will submit the best one for the contest. A judging panel will select the overall UK winning case and this will be put forward for the World Final.

Alongside the opportunity for dental students to practise composite layering techniques with the innovative Ceram.X composite, there are terrific prizes along with, of course, the kudos that comes from competing against global peers to become the best Dentsply Ceram.X dental student in the world.

The deadline for UK entries is 28 February 2012.

Reader response number 56

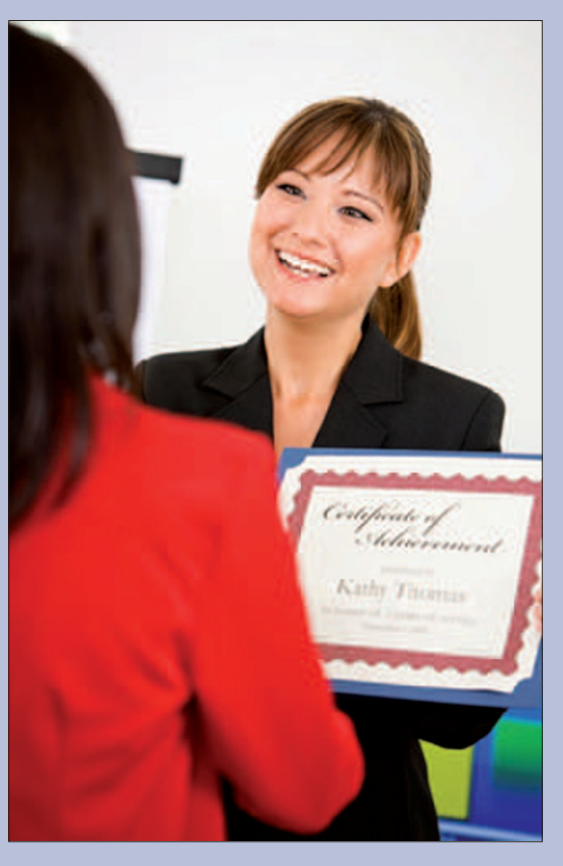

